\title{
Writing about Math for the Perplexed and the Traumatized
}

\author{
Steven Strogatz
}

\section{Introduction}

In the summer of 2009 I received an unexpected email from David Shipley, the editor of the op-ed page for the New York Times. He invited me to look him up next time I was in the city and said there was something he'd like to discuss.

Over lunch at the Oyster Bar restaurant in Grand Central Station, he asked whether I'd ever have time to write a series about the elements of math aimed at people like him. He said he'd majored in English in college and hadn't studied math since high school. At some point he'd lost his way and given up. Although he could usually do what his math teachers had asked of him, he'd never really seen the point of it. Later in life he'd been puzzled to hear math described as beautiful. Could I convey some of that beauty to his readers, many of whom, he suspected, were as lost he was?

I was thrilled by his proposition. I love math, but even more than that, I love trying to explain it. Here I'd like to touch on a few of the writing challenges that this opportunity entailed, along with the goals I set for myself, and then describe how, by borrowing from three great science writers, I tried to meet those challenges. I'm not sure if any of my suggestions will help other mathematicians who'd like to share their own love of math with the public, but that's my hope.

\section{Three Challenges}

One challenge in writing about math is that the subject is inherently abstract. The objects of

Steven Strogatz is the Schurman Professor of Applied Mathematics at Cornell University. His email address is strogatz@corne11.edu.

This essay is adapted, with permission, from a chapter to appear in The Power of Writing, edited by Christiane Donahue, to be published by the University Press of New England on behalf of Dartmouth College Press.

DOI: http://dx.doi.org/10.1090/noti1086 mathematics are disembodied ideas, not people or stories or things. Although its simplest concepts, numbers and shapes, aren't too hard for most readers to grasp, math becomes increasingly slippery and ethereal as we move on to formulas and functions, theorems and proofs, derivatives and integrals.

Then there's the matter of the strange symbols and jargon. The uninitiated have no idea how to say something like $\oint$. And what on earth is a directrix or, worse yet, a latus rectum?

Finally, attention must be paid to the psychiatric dimensions of the subject. Math is linked in the popular mind with phobia and anxiety. You'd think we were discussing spiders. So anyone hoping to write about math for a wide audience needs to reckon with the reality that math is, for many people, terrifying. Boring. Meaningless. And, in the most florid cases, all of the above.

\section{Three Audiences}

After years of listening to people's emotional stories about their experiences with math, I've come to recognize three broad groups into which all of humanity falls (I'm kidding, of course, but not entirely):

1) The traumatized: These folks suffered humiliation somewhere along the line, maybe as early as second or third grade when they were subjected to the arcana of borrowing and carrying. Or maybe they hit the wall at long division, word problems, or linear algebra. In any case, for these wounded souls math is now an unhappy memory, a lasting blow to the ego. "I'm just not a math person." "I don't have a head for numbers." "I loved math until I got to (insert tricky math concept here)." Other subjects can inflict the same kind of damage but not to the same degree and not quite so painfully as math does. 
2) The perplexed: This is David Shipley's camp. For him and his ilk, math left no scars; it merely felt pointless. These are the people who never quite knew what they were doing mathematically, yet they compensated by working hard, following directions, and overcoming failures. A large proportion of successful people fall into this campessentially anyone who wasn't a natural at math.

3) The naturals: Though it's taboo to admit it, I believe there are some kids who have a feel for math. It makes sense to them and gives them pleasure and satisfaction. They may or may not get good grades; that depends more on how hard they work and how well they play the game of school. But the talent is there. In rare cases, they grow up to become mathematicians. Or they may go into a related field: accounting, engineering, computers, finance, medicine, etc. Or, most likely of all, they never use math again after they join the workforce. Nonetheless, they retain a lifelong affection for it. These are the people who used to read Martin Gardner's "Mathematical Games" column in Scientific American. Almost all books, blogs, and magazine articles on "popular math" are directed toward them and them alone.

That's why, as crude as this classification scheme may be, it's useful. It helps us to see that groups 1 and 2-the traumatized and the perplexed-are underserved mathematically. Though David Shipley didn't put it this way, he was asking me to write for them.

\section{The Need for Empathy}

Whether I'm teaching a class, tutoring one-on-one, writing for my colleagues in other scientific disciplines, or trying to convey the beauty of math to the wider public, I've learned that explaining math successfully is not mainly about the logic and clarity of the explanation. (Those are necessary but not sufficient.) Explaining math well requires empathy. The explainer needs to recognize that there's another person on the receiving end of the explanation. But in our culture of mathematics, an all-too-common approach is to state the assumptions, state the theorems, prove the theorems, and stop. Any questions?

What makes this approach so ineffective is that it answers questions the student hasn't thought to ask. On top of that, it can be exhausting to follow someone else's train of thought. A captive audience of students has no choice, of course; they're forced to listen and yield. That's how we, as math teachers, get in the habit of forgetting to empathize.

If you want someone to follow your mathematical disquisitions voluntarily-or better yet, happily-you have to help him or her love the questions you're asking. This is true for any audience, but especially for the traumatized and the perplexed. You have to help them love the questions.

But how?

\section{Three Routes to Mathematical Seduction}

For any would-be pop math writer, here are a few surefire techniques.

(1) Illuminate. Give the reader a shiver of pleasure by providing an "Aha!" experience.

(2) Make connections. Tie the math to something the reader already enjoys.

(3) Treat the reader like a friend of yours-a nonmathematical friend. Then you'll instinctively do everything right.

In what follows I'll try to flesh out what I mean by these techniques and show how three giants of science writing-Richard Feynman, Stephen Jay Gould, and Lewis Thomas - served as inspirations to me.

\section{Provide Illumination}

Moments of illumination help a reader fall in love with math, especially after struggling in the dark for so long.

The illumination can be purely verbal. In one of my articles I pointed out why fractions like $2 / 3$ or $1 / 4$ are called "rational numbers"-they involve ratios of whole numbers. This struck my wife, Carole, as an epiphany. She had always labored under the misimpression that rational numbers were somehow more reasonable than "irrational" numbers, but she could never see what was so flighty or hysterical about the latter. Now she understood. Irrational numbers are simply those that can't be expressed as a ratio of two whole numbers. They're ir-ratio-nal.

Another revelation for her had to do with the word "squared". No teacher had ever bothered to explain that "2 squared" is synonymous with 2 times 2 and " 3 squared" with 3 times 3 because collections of that many objects can be arranged in the shape of a square:

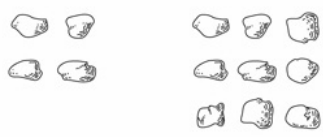

On other occasions in the series, I tried to illuminate the reasoning behind mathematical statements that all of us heard in school but that few of us ever really understood, such as why a negative times a negative is a positive or where the formula for the area of a circle comes from.

\section{Make Connections}

Math becomes more appealing when it's tied to topics the reader cares about. Sports, music, literature, movies, science, business, law-they're all great sources of math in action. For anyone who likes to get physical, vectors seem a lot more vivid when they're illustrated by samba dance steps or how Roger Federer hits his running forehand down the line. For history buffs the rules for multiplying negative and positive numbers come to life when you show how much sense they can make of the 
shifting alliances among European countries in the runup to World War I.

Making the effort to include real-world connections like these sends a message to the reader: Even if you are not primarily interested in math, you are welcome here. This is what the perplexed and the traumatized need to hear. Connection, not alienation.

\section{Be a Friend}

Adopting a welcoming tone comes automatically if you picture the reader as a living, breathing, nonmathematical friend of yours. Rather than writing for a generic "intelligent reader", I imagined a real person when I wrote for the Times. It felt right to open the series by mentioning him, to establish an informal, affectionate tone and also to hint at the ideal reader I had in mind:

\begin{abstract}
I have a friend who gets a tremendous kick out of science, even though he's an artist. Whenever we get together all he wants to do is chat about the latest thing in evolution or quantum mechanics. But when it comes to math, he feels at sea, and it saddens him. The strange symbols keep him out. He says he doesn't even know how to pronounce them.

In fact, his alienation runs a lot deeper. He's not sure what mathematicians do all day, or what they mean when they say a proof is elegant. Sometimes we joke that I just should sit him down and teach him everything, starting with $1+1=2$ and going as far as we can. ([Strogatz], "From Fish to Infinity")
\end{abstract}

I found that when thinking about specific tactical decisions in my writing, this orientation-treating the reader as a friend-always suggested what to do. For instance, it nudged me to make the following choices:

1) Keep algebraic manipulations to a minimum. My artist friend panics when the math gets too symbolic. The same is true for most of the perplexed and the traumatized. They get turned off by equations and shut down emotionally. It's much better, where possible, to recast the same mathematical idea pictorially.

2) Likewise, avoid sophisticated math symbols. Since most of the target readers won't know how to pronounce them, they won't be able to sound them out in their heads, which will tempt them to stop reading.

3) Don't number the diagrams. That gives them a textbook feel, another turn off. And don't automatically place them at the top or bottom of the page (contrary to what most publishers would do by default). Instead, insist that the diagrams be placed in the text, surrounded by the words they illustrate. This is a friendly gesture; it saves the reader the trouble of hunting around for the diagram. In the same spirit, I asked my artist, Margy Nelson, to draw the diagrams in a cartoonish style. The hope was that the levity would refresh the reader when the going got tough.

\section{Three Heroes}

The strategies I've described here are all devices to help an outsider feel welcome. Three superb science writers-Richard Feynman, Stephen Jay Gould, and Lewis Thomas-approach this issue with exceptional flair. They take subjects that many readers would find forbidding - the edifice of modern physics, the vagaries of evolution, and the marvels of biology-and open the door for everyone.

\section{Richard Feynman}

What you notice first about Richard Feynman is his voice. He's conversational, direct, and funny, always plain-spoken, but sometimes surprisingly lyrical. He comes across as a rascal; a playful, mischievous Brooklyn wise guy.

In his celebrated three-volume set of textbooks, The Feynman Lectures on Physics, here's how he opens his chapter on the principle of least action, one of the deepest ideas in all of physics:

When I was in high school, my physics teacher-whose name was Mr. Badercalled me down one day after physics class and said, "You look bored; I want to tell you something interesting." Then he told me something which I found absolutely fascinating, and have, since then, always found fascinating. Every time the subject comes up, I work on it. In fact, when I began to prepare this lecture I found myself making more analyses on the thing. Instead of worrying about the lecture, I got involved in a new problem. The subject is this - the principle of least action. ([Feynman], Volume II, page 19-1)

With his conversational style, he seems to be saying that physics is hard enough as it is - there's no need to make it harder by using fancy language or by putting on the formal airs of a textbook writer.

And he revels in telling the truth, especially about what remains unknown. For example, in another chapter he prefaces a discussion of thunderstorms by stressing how little we know about this commonplace phenomenon:

What is going on inside a thunderstorm? We will describe this insofar as it is known. As we get into this marvelous phenomenon of real nature-instead of the idealized spheres 
of perfect conductors inside of other spheres that we can solve so neatly-we discover that we don't know very much. Yet it is really quite exciting. Anyone who has been in a thunderstorm has enjoyed it, or has been frightened, or at least has had some emotion. And in those places in nature where we get an emotion, we find that there is generally a corresponding complexity and mystery about it. ([Feynman], Vol. II, page 9-5)

Any student reading this feels reassured. Not only is it okay not to know something, it's exciting, because that's where new science is made-on the border between the known and the unknown. Feynman, one of the greatest physicists of the twentieth century, takes you there as your personal tour guide.

I had Feynman in mind when I wrote about calculus for the Times series. Knowing that many readers would quake at the thought of calculus as the Mount Everest of math, I tried to disarm their fears without dismissing them, by casting my dad in the role of everyman, and by mimicking Feynman's affable style:

Long before I knew what calculus was, I sensed there was something special about it. My dad had spoken about it in reverential tones. He hadn't been able to go to college, being a child of the Depression, but somewhere along the line, maybe during his time in the South Pacific repairing B-24 bomber engines, he'd gotten a feel for what calculus could do. Imagine a mechanically controlled bank of anti-aircraft guns automatically firing at an incoming fighter plane. Calculus, he supposed, could be used to tell the guns where to aim.

Every year about a million American students take calculus. But far fewer really understand what the subject is about or could tell you why they were learning it. It's not their fault. There are so many techniques to master and so many new ideas to absorb that the overall framework is easy to miss.

Calculus is the mathematics of change. It describes everything from the spread of epidemics to the zigs and zags of a well-thrown curveball. The subject is gargantuan-and so are its textbooks. Many exceed 1,000 pages and work nicely as doorstops. ([Strogatz], "Change We Can Believe In")
But what I find most inspiring in Feynman's writing, and what I try to emulate in my own work, is his knack for delivering Aha! moments. His explanations, though phrased colloquially, are impeccable. They go straight to the heart of the matter. On almost any topic in any branch of physics, you will not find a more elegant and satisfying explanation than the one Feynman offers. He is the master of illumination.

\section{Stephen Jay Gould}

In contrast to Feynman, Stephen Jay Gould is the master of connections. Whereas Feynman lives and breathes for physics and physics alone, Gould links his subject, evolution, to the rest of existence in glorious detail. His essays range over science, history, philosophy, politics, architecture, and all parts of culture, high and low.

Two of his most famous essays draw on principles of evolutionary biology to explain why there are no longer any .400 hitters in baseball and why Mickey Mouse's facial features became progressively less rat-like and more adorably infantile (big eyes, big head, rounded features) over his first fifty years. In other pieces he explains why large animals have relatively thick leg bones, how insects walk up walls, why toddlers aren't hurt when they fall down, why medieval churches changed shape as they got larger, and how the creators of science fiction and horror movies embarrass themselves by overlooking these principles of size and scale when they depict giant ants or tiny people.

One of Gould's signature moves is to hook you with something light and unthreatening - a word, a story, a joke-to ease you into something sophisticated, the real subject of the piece. For instance, in his essay "Senseless signs of history" he introduces a subtle idea in evolutionary biology, that "oddities in current terms are the signs of history," by coming in from the side like so:

Words provide clues about their history when etymology does not match current meaning. Thus, we suspect that emoluments were once fees paid to the local miller (from the Latin molere, to grind), while disasters must have been blamed upon evil stars.

Evolutionists have always viewed linguistic change as a fertile field for meaningful analogies. Charles Darwin, advocating an evolutionary interpretation for such vestigial structures as the human appendix and the embryonic teeth of whalebone whales, wrote: " $\mathrm{Ru}$ dimentary organs may be compared with the letters in a word, still retained in the spelling, but become useless in the pronunciation, but which serve as a 
clue in seeking for its derivation." Both organisms and languages evolve...

Darwin reasoned that, if organisms have a history, then ancestral stages should leave remnants behind. Remnants of the past that don't make sense in present terms-the useless, the odd, the peculiar, the incongruous-are the signs of history. They supply proof that the world was not made in its present form. ([Gould], Chapter 2, pp. 27-29)

I tried a similar sideways approach in the opening paragraphs of my column about group theory:

My wife and I have different sleeping styles-and our mattress shows it. She hoards the pillows, thrashes around all night long, and barely dents the mattress, while I lie on my back, mummylike, molding a cavernous depression into my side of the bed.

Bed manufacturers recommend flipping your mattress periodically, probably with people like me in mind. But what's the best system? How exactly are you supposed to flip it to get the most even wear out of it?

Brian Hayes explores this problem in the title essay of his recent book, "Group Theory in the Bedroom." Double entendres aside, the "group" in question here is a collection of mathematical actions-all the possible ways you could flip, rotate or overturn the mattress so that it still fits neatly on the bed frame.

By looking into mattress math in some detail, I hope to give you a feeling for group theory more generally. It's one of the most versatile parts of mathematics. It underlies everything from the choreography of contra dancing and the fundamental laws of particle physics, to the mosaics of the Alhambra.... ([Strogatz], "Group Think")

Unlike Feynman, however, Gould does not talk to you. He lectures at you. I never feel that he's my friend, and I wouldn't want to be stuck with him on a long car ride.

\section{Lewis Thomas}

My dream companion would be Lewis Thomas. He's funny and sunny, the most amiable science writer I've ever read. It's not that he doesn't see the world as it is, warts and all. It's that, for him, even the warts are wonderful:
Warts are wonderful structures. They can appear overnight on any part of the skin, like mushrooms on a damp lawn, full grown and splendid in the complexity of their architecture. Viewed in stained sections under a microscope, they are the most specialized of cellular arrangements, constructed as though for a purpose. They sit there like herded mounds of dense, impenetrable horn, impregnable, designed for defense against the world outside....

The strangest thing about warts is that they tend to go away. Fully grown, nothing in the body has so much the look of toughness and permanence as a wart, and yet, inexplicably and often very abruptly, they come to the end of their lives and vanish without a trace.

And they can be made to go away by something that can only be called thinking, or something like thinking. This is a special property of warts which is absolutely astonishing, more of a surprise than cloning or recombinant DNA or endorphin or acupuncture or anything else currently attracting attention in the press. It is one of the great mystifications of science: warts can be ordered off the skin by hypnotic suggestion. ([Thomas], "On Warts”, p. 61)

This is the delight of Lewis Thomas. He sees the universe in a grain of sand or, in his case, in a wart.

He's also, for my money, the best stylist of all science writers. His sentences have a lilt and a rhythm and a snap to them. So do his words and his paragraphs. He's graceful at every scale, from punctuation to paragraph. Read this passage out loud to hear what I mean:

The capacity to blunder slightly is the real marvel of DNA. Without this special attribute, we would still be anaerobic bacteria and there would be no music. Viewed individually, one by one, each of the mutations that have brought us along represents a random, totally spontaneous accident, but it is no accident at all that mutations occur; the molecule of DNA was ordained from the beginning to make small mistakes.

If we had been doing it, we would have found some way to correct this, and evolution would have been stopped in its tracks. Imagine the consternation of human scientists, successfully engaged in the letter-perfect replication 
of prokaryotes, nonnucleated cells like bacteria, when nucleated cells suddenly turned up. Think of the agitated commissions assembled to explain the scandalous proliferation of trilobites all over the place, the mass firings, the withdrawal of tenure. ([Thomas], "The Wonderful Mistake”, p. 23)

I especially love his surprising juxtapositions. Sometimes they come in staccato bursts, like a prizefighter throwing a combination: "The capacity to blunder slightly is the real marvel of DNA. Without this special attribute, we would still be anaerobic bacteria and there would be no music." Bang, bang, bang, boom!

I was hoping to achieve a similar effect, in muted form, in this opening to a piece about differential geometry:

The most familiar ideas of geometry were inspired by an ancient vision-a vision of the world as flat. From parallel lines that never meet, to the Pythagorean theorem discussed in last week's column, these are eternal truths about an imaginary place, the two-dimensional landscape of plane geometry. ([Strogatz], "Think Globally")

Saying something nice about flat-earth thinking and juxtaposing eternal truths and imaginary places was my attempt (pale as it may have been) to play with the reader's expectations in the manner of Lewis Thomas.

Although Feynman, Gould, and Thomas use different tactics, it seems to me that they've all converged on the same secret, the key to communicating difficult technical subjects to the masses. Clear writing? Sure. Beautiful explanations? Of course. But none of that is enough.

The real secret is empathy. These heroes of science writing help us love the questions they're asking. They do whatever it takes to make us feel at home in a strange land.

\section{Epilogue}

My New York Times series "The Elements of Math" debuted on January 31, 2010. The response from readers far surpassed what I could have dreamed of. For fifteen straight weeks, the columns attracted hundreds of comments and climbed the list of most emailed articles, occasionally reaching \#1. Here are a few sample reactions to the first column:
- Great! I am a math phobic, an artist, but very curious to learn again in a new way. I am excited!

- This is exciting! I'm an English teacher, but also a science enthusiast. I've always, however, been hobbled by my poor math skills. What a testament to the survival of intellect, that a column about mathematics could generate buzz and (at this writing) almost 500 positive and encouraging comments. I look forward to this. Thank you.

My favorite reaction, though, came from my neighbor Lauren, a photographer. She said that reading my series made her want to like math.

Not quite what I was shooting for, but hey, it's a start.

\section{Bibliography}

[Feynman] RichaRd P. FEYNMAN, ROBERT B. LEIGHTON, and MATTHEW SANDS, The Feynman Lectures on Physics, Addison-Wesley, 1964.

[Gould] STEPHEN JAY GOULD, The Panda's Thumb: More Reflections in Natural History, W.W. Norton \& Company, 1980.

[Strogatz] STEVEn Strogatz, The Elements of Math, The New York Times, 2010. Available online at http:// topics.nytimes.com/top/opinion/series/ steven_strogatz_on_the_elements_of_math/ index.htm 1 and in slightly modified form in Steven Strogatz, The Joy of x: A Guided Tour of Math, from One to Infinity, Houghton Mifflin Harcourt, 2012.

[Thomas] LewIS ThomAs, The Medusa and the Snail: More Notes of a Biology Watcher, Bantam Books, 1980.
- Thank you thank you thank you! I've been waiting for you all my adult life. I've always felt I am colour-blinded for math; perhaps this time around I'll finally be able to make friends with it....

- We, the innumerate, thank you. 